\title{
Surface Modification of Synthetic Clay Aimed at Biomolecule Adsorption: Synthesis and Characterization
}

\author{
Angela de Mello Ferreira Guimarães ${ }^{\mathrm{a} *}$, Virgínia Sampaio Teixeira Ciminelli ${ }^{\mathrm{b}}$, Wander Luiz Vasconcelos ${ }^{\mathrm{b}}$ \\ ${ }^{a}$ Departament of Engineering, Minas Gerais Federal Center for Technological Education, \\ Av. Amazonas, 7675, Nova Gameleira, 30510-000 Belo Horizonte - MG, Brazil \\ ${ }^{\mathrm{b}}$ Departament of Metallurgical and Materials Engineering, Federal University of Minas Gerais \\ Rua Espírito Santo, 35, Centro, 30160-030 Belo Horizonte - MG, Brazil
}

Received: August 22, 2006; Revised: December 20, 2006

\begin{abstract}
This work describes the process for functionalization of laponite through the grafting of 3mercaptopropyltrimethoxysilane (MPTS). Laponite is synthetic smectite clay with surface area of $350 \mathrm{~m}^{2} / \mathrm{g}$. The samples, prior to and after functionalization, were characterized by chemical analyses, thermogravimetric analysis (TGA), x ray diffraction (XRD), diffuse reflectance infrared Fourier transform spectroscopy (DRIFT), scanning electron microscopy and energy dispersive spectrometry (MEV/EDS). Infrared spectroscopy and elemental analyses confirmed the presence of organic chains and thiol groups in the modified clay. The immobilized and available thiol group, measured according to the Volhard method, totaled $1.4 \mathrm{meq} / \mathrm{g}$ of clay, with approximately 90\% accessible for $\mathrm{Ag}^{+}$trapping. These results represent an improvement as compared to other works concerning the functionalization of smectite-type clays in which the effect produced by functional group blockage limits the access of species to less than $10 \%$ of the complexing sites.
\end{abstract}

Keywords: laponite, functionalization, biomolecule adsorption

\section{Introduction}

Mineral clays of the smectite group present a set of structural characteristics that make them attractive for the development of catalysts, sorbents, supports for drug or enzymes, and intercalation of organic molecules ${ }^{1-5}$. Organosilanes are widely used for the modification of silica surfaces. The silylation mechanism for the attachment of organosilane to amorphous silica and alumina surfaces has been commonly reported ${ }^{6-8}$. Recently, organosilanes have been employed for the modification of layered silicates, with smectites and vermiculites being the most commonly clays used to investigate the functionalization processes ${ }^{9-12}$. Among the smectites, montmorillonite has been the most common choice, mostly due to its availability and adequate characteristics of expandability ${ }^{12}$. More recently, the functionalization of other clays, such as the synthetic laponite, has been also studied for various applications. These include i) the preparation of organosilasesquioxane-laponite clay films on solid electrodes and their subsequent use as electrochemical (bio) sensors ${ }^{2,13,14}$; ii) the immobilization of several enzymes within clay matrices ${ }^{15}$; iii) the immobilization of catalysts ${ }^{5}$ and iv) the removal of undesirable bimolecules from extractors and slurry ${ }^{16}$.

Laponite is a layered hydrous magnesium silicate, hydrothermally synthesized from mixing silicate, lithium, and magnesium salts in the presence of mineralizing agents. This clay is normally used as a rheology modifier for a wide range of industrial and consumer products and to produce electrically conductive, antistatic, and barrier thin coatings. Laponite is an entirely synthetic smectite clay, which closely resembles the natural clay mineral hectorite in both structure and composition, and has a specific surface area of $350 \mathrm{~m}^{2} / \mathrm{g}$. Laponite can be described by the chemical formula of $\mathrm{Na}_{0.7}\left[\left(\mathrm{Si}_{8} \mathrm{Mg}_{5.5} \mathrm{Li}_{0.3}\right)\right.$ $\left.\mathrm{O}_{20}(\mathrm{OH})_{4}\right]$ and is made up of small disc-like particles. Each singleparticle is a crystalline disc with an average radius of $20 \mathrm{~nm}$ and a thickness of $1.0 \mathrm{~nm}$. Only in dilute suspension, the charged platelets

*e-mail: angelamello@des.cefetmg.br

Article presented at the IV Congresso Latino Americano de Orgãos Artificiais e Biomateriais (COLAOB 2006), August 8 and 11, 2006, Caxambu, MG, Brazil become dispersed as individual units. In a dry form, these units are usually agglomerated into larger clusters. The silanol groups located at the edges of the laponite sheets may be used to covalently attach themselves to organic compounds. The lamellar spacing of laponite may be expanded to incorporate intercalants ${ }^{17}$.

Surface modification is a key step concerning the application of clays in biotechnology. One of the main obstacles hindering these applications is the interaction of organic molecules with the acid and hydrophilic clay surface, which in turn may cause the denaturation of enzymes ${ }^{15}$. This limitation can be overcome by passivating the acid surface sites and creating a more organophilic clay matrix with different functionalities. The clay surface may be modified through reactions with various functional groups, such as thiol, amine, or long carbon chains.

The present study was aimed to developing clay-based materials that can be used as sorbents for biomolecules. This work focused on the functionalization of a synthetic clay with thiol groups through the grafting of 3-mercaptopropyltrimethoxysilane (MPTS). A detailed material characterization was provided by chemical analysis, diffuse reflectance infrared Fourier transform spectroscopy-DRIFT, $x$ ray diffraction-XRD, scanning electron microscopy and energy dispersive spectrometry - MEV/EDS. The sorption capacity of the mercaptyl functional groups in the clay was evaluated using the Volhard silver nitrate method.

\section{Experimental Procedures}

\subsection{Materials}

The laponite sample used in the experiments was supplied by Rockwood Specialties Inc. and is identified by the chemical formula $\mathrm{Na}_{0.7}\left[\left(\mathrm{Si}_{8} \mathrm{Mg}_{5.5} \mathrm{Li}_{0.3}\right) \mathrm{O}_{20}(\mathrm{OH})_{4}\right]$. According to the supplier, the 
material has a specific density of 2.53 and cation exchange capacity (CEC) of 50 to $60 \mathrm{meq} / 100 \mathrm{~g}$ of clay. When fully dispersed in water, the particles display disc-shaped, nano-sized crystals of approximately $20 \mathrm{~nm}$ in diameter and $1 \mathrm{~nm}$ in thickness. The organosilanegrafting agent, the 3-mercaptopropyltrimethoxysilane (MPTMS) $\left(\mathrm{Si}\left(\mathrm{OCH}_{3}\right)_{3} \mathrm{C}_{3} \mathrm{H}_{6} \mathrm{SH}\right), 98 \%$ pure, was purchased from Sigma-Aldrich and used without further purification. Toluene (99.8\%) was also provided by Sigma-Aldrich. The solutions of $\mathrm{AgNO}_{3}, \mathrm{KSCN}$, and $\mathrm{Fe}\left(\mathrm{NH}_{4}\right)\left(\mathrm{SO}_{4}\right)_{2}$ used in the adsorption experiments were prepared with reagent grade chemicals (Merck). All solutions were prepared with high-purity water $\left(18 \mathrm{M} \Omega . \mathrm{cm}^{-1}\right)$ obtained from a MilliQ water purification system.

\subsection{Modification process}

Prior to the grafting process, $1 \mathrm{~g}$ of the sodic laponite (LNa) was acid activated with $100 \mathrm{~mL}$ of $0.1 \mathrm{~mol} / \mathrm{L} \mathrm{HCl}$ solution. This suspension was maintained under agitation for 6 hours; the resulting sample was denominated $\mathrm{LH}$. The acid activation was used to remove the sodium ions from the interlamelar region. In a next step, $1 \mathrm{~g}$ of acid activated laponite, previously dried at $150{ }^{\circ} \mathrm{C}$ for 4 hours, was dispersed in $50 \mathrm{~cm}^{3}$ of $0.1 \mathrm{~mol} / \mathrm{L}$ MPTMS in dry toluene. The resulting mixture was refluxed and agitated for 24 hours within an inert atmosphere of $\mathrm{N}_{2}$ to avoid the oxidation of the group SH. The obtained solid was sequentially washed with toluene, absolute ethyl alcohol, and MilliQ water, filtered and dried for 2 hours at $120{ }^{\circ} \mathrm{C}$ in an inert nitrogen atmosphere. The functionalized sample was denominated LHSH. This method is similar to that described by Walcarius et al. ${ }^{6}$ for the functionalization of silica gel.

\subsection{Characterization methods}

The $\mathrm{x}$ ray diffraction patterns of modified and unmodified clay samples were obtained with a Philips model PW1710 diffractometer, fitted with a $\mathrm{Cu}$ tube $(\lambda=1.5418 \AA$, $40 \mathrm{kV}$ and $20 \mathrm{~mA}$, step size $\left.0.06^{\circ} 2 \theta, 5 \mathrm{~s} / \mathrm{step}\right)$. DRIFT analyses were performed using a FT/IR- spectrophotometer, model SPECTRUM-1000, Perkin Elmer ( 32 scans of accumulation; resolution of $4 \mathrm{~cm}^{-1}$ ). The IR measurements were taken at room temperature, in the spectral range of $400-4000 \mathrm{~cm}^{-1}$. The samples were mixed with $\mathrm{KBr}$ powder in 5 wt. (\%) and a pure $\mathrm{KBr}$ spectrum was used as reference. Thermogravimetric curves were obtained in a TGA model TGA50 Shimadzu under in $\mathrm{N}_{2}$ environment, $(20 \mathrm{~mL} / \mathrm{min})$, with temperature ramp of $10{ }^{\circ} \mathrm{C} / \mathrm{min}$ between $30{ }^{\circ} \mathrm{C}-1000{ }^{\circ} \mathrm{C}$. The morphological and semiquantitative analyses of the samples was carried out in a Scanning Electron Microscopy (Jeol instrument model JSM-6360LV, operating at $25 \mathrm{kV}$ and with a Noran energy-dispersive spectrometer (ZAF corrections coupled).

\subsection{Binding capacity of the mercaptyl functional groups}

In the present investigation, the amount of the immobilized and accessible thiol groups was successfully determined according to a protocol based on the Volhard silver nitrate method ${ }^{18}$ developed by the authors. The determination is based on the chemical affinity of silver by the thiol groups. Following the protocol, $25 \mathrm{~mL}$ of $0.01 \mathrm{~mol} / \mathrm{L}$ silver nitrate solution were added to flasks containing $100 \mathrm{mg}$ of dry modified clay. The flasks were covered to avoid exposure to light and stirred in a shaker for $3 \mathrm{~h}$ prior to testing. The remaining silver nitrate was titrated with standardized $0.01 \mathrm{~mol} / \mathrm{L}$ potassium thiocyanate (KSCN) using iron ammonium sulfate hexahydrate as an indicator. The endpoint was detected when an excess of thiocyanate anion formed a red colored complex with the iron compound. The binding capacity of the mercaptyl functional group was expressed in meq/g of clay. In all cases the tests were carried out in triplicate and the results compared with those obtained using a sample of unmodified clay as a reference. Another flask containing pure solution was submitted to the same process in order to evaluate eventual precipitation. This methodology was used as protocol to quantify the accessible $\mathrm{SH}$ groups. The sequence of reactions is described below:

Adsorption step:

$$
\begin{aligned}
& \sim \mathrm{RSH}_{(\mathrm{S})}+\mathrm{AgNO}_{3(\mathrm{aq})} \rightarrow \sim \mathrm{RSAg}_{(\mathrm{s})}+\mathrm{HNO}_{3(\mathrm{aq})} \\
& \text { (modified clay) }
\end{aligned}
$$

Titration step:

$$
\begin{aligned}
& \mathrm{AgNO}_{3(\mathrm{aq})}+\mathrm{KSCN}_{(\mathrm{aq})} \rightarrow \mathrm{AgSCN}_{(\mathrm{S})}+\mathrm{KNO}_{3(\mathrm{aq})} \\
& \begin{aligned}
& \text { End point: } \\
& 6 \mathrm{SCN}^{-}{ }_{(\mathrm{aq})}+\mathrm{Fe}^{3+}{ }_{(\mathrm{aq})} \rightarrow \mathrm{Fe}(\mathrm{SCN})_{6}^{3-}{ }_{(\mathrm{aq})} \\
&(\text { Red complex })
\end{aligned}
\end{aligned}
$$

\section{Results and Discussion}

\subsection{Functionalization process}

The silylation of silicates involves a direct condensation reaction between the terminal $(\mathrm{OH})$ groups from the silicate surface and the species derived from the hydrolysis of the alkoxysilanes. It is believed that the silylation of silicate is favored over the polysiloxane formation if the reaction is conducted in a dry environment. Figure 1 depicts a schematic illustration of the functionalization process followed by biomolecule adsorption. The silane coupling agents are a family of organosilicon monomers with the general structure of $\mathrm{R}-\mathrm{SiX}_{3}$. $\mathrm{X}$ is the hydrolyzable alkoxy group, typically methoxy $\left(-\mathrm{OCH}_{3}\right)$ or ethoxy $\left(-\mathrm{OC}_{2} \mathrm{H}_{5}\right)$, which releases methanol and ethanol during the coupling reactions. $\mathrm{R}$ is an organo-functional group attached to silicon. Some recent works have shown that it is possible to create specific chemical activity through the selection of an adequate functional group, in a way that the functionalized clay will provide specific sites for the adsorption of specific enzymes ${ }^{4}$. In the present work, the mercapto group was selected as functional group due to its great affinity to many biomolecules.

Following functionalization, the concentration of the immobilized thiol groups in the clay was measured according to the Volhard

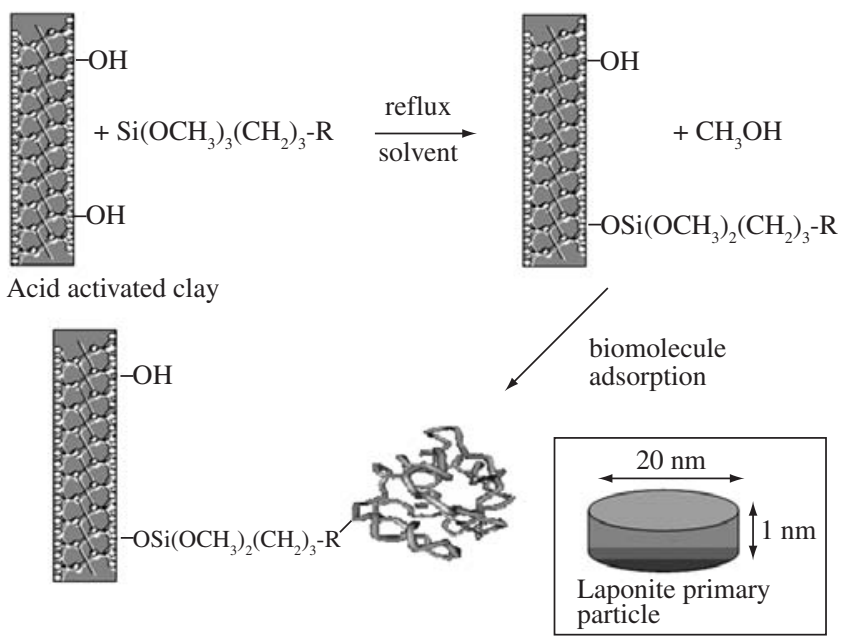

Figure 1. Schematic illustration of the direct hydrolysis and condensation reaction followed by biomolecule adsorption. The inset shows a schematic representation of the size and morphology of the individual clay platelets (the "primary particles"). 
method. The total binding capacity was determined as $1.4 \mathrm{meq} / \mathrm{g}$ and $0.15 \mathrm{meq} / \mathrm{g}$ for the functionalized and the original clay (LNa), respectively. It indicates that the mechanism of adsorption involves primarily silver ion complexation by the thiol groups instead of cation exchange. The unmodified sample exhibits some ion immobilization capacity that may be related to a cation exchange mechanism, even though the original sample shows a very low affinity for silver ions. The average CEC indicated by the supplier is of $0.55 \mathrm{meq} / \mathrm{g}$.

The value is comparable to the values obtained by Dominguez \& Yue in a synthesis of mercaptyl fibers $(1.7 \mathrm{meq} / \mathrm{g})^{18}$. It is important to note that the method of silver titration may provide non-differentiating results for both thiols and disulfide groups, since the latter also form very stable complexes with silver ions ${ }^{18}$.

Elemental semi-quantitative analyses provided by EDS are summarized in Table 1 . The atomic \% ratio, $\mathrm{Si} / \mathrm{Mg}$, increases from 1.9 to 2.4 after acid treatment, thus indicating that clay dissolution has occurred to some extent with a consequent release of $\mathrm{Mg}^{2+}$ from the clay lattice. We believe that this reaction may increase the density of $\mathrm{Mg}-\mathrm{OH}$ and $\mathrm{Si}-\mathrm{OH}$ groups on clay surface and thereby improve the organosilane immobilization, since this immobilization involves a reaction with the silicate's $\mathrm{OH}$ groups. The increase of the atomic $\%$ ratio, $\mathrm{Si} / \mathrm{Mg}$, in the $\mathrm{LHSH}-\mathrm{Ag}$ sample is related to the incorporation of the organosilane molecule. The atomic \% ratio, $\mathrm{Ag} / \mathrm{S}$, in this sample suggests that almost all of the mercaptyl groups $(\sim 90 \%)$ were accessible to silver binding. This presents a positive result, once Mercier \& Detellier who reported that the intercalation of 3(mercaptopropyl)trimethoxysilane in the galleries of smectite-type clay led to loadings corresponding to less than $10 \%$ of the total number of thiol groups in the adsorbent ${ }^{10}$. An improvement of the previous result was later reported by Mercier \& Pinnavaia who prepared an MPTS-fluorohectorite and found that $67 \%$ of the thiol groups were accessible for $\mathrm{Hg}$ (II) ions ${ }^{9}$. This result is similar to those reported by Celis et al. for MPTS-sepiolite ${ }^{1}$. These authors attributed the relatively low loading to the blockade of pore space by intercalated molecules.

\subsection{Sample characterization}

The DRIFT spectra of modified and unmodified clay are presented in Figure 2. Changes following the modification process can be observed in all frequency range of the FTIR spectra. The spectrum of the sodium laponite ( $\mathrm{LNa}$ ) exhibits a broad shoulder at around $3700-3400 \mathrm{~cm}^{-1}$, in a range of frequencies usually assigned to surface hydroxyl groups and sorbed water. This poorly resolved shoulder consists of the overlapping of two components: $\mathrm{Si}-\mathrm{OH}\left(\right.$ at $\left.3628 \mathrm{~cm}^{-1}\right)$ and $\mathrm{Mg}-\mathrm{OH}$ (at $3686 \mathrm{~cm}^{-1}$ ) stretching vibrations ${ }^{5}$ and the $v(\mathrm{O}-\mathrm{H})$ stretching frequency at $3450 \mathrm{~cm}^{-1}$ due to physisorbed water. The $\delta(\mathrm{O}-\mathrm{H})$ deformation band at $1640 \mathrm{~cm}^{-1}$ is yet another indication of the presence of water ${ }^{19}$. In the low energy region, the spectrum shows one broad band with a maximum peak at $1010 \mathrm{~cm}^{-1}$ assigned to $\mathrm{Si}-\mathrm{O}$ and Si-O-Si stretching vibrations, one band around $660 \mathrm{~cm}^{-1}$ due to $\mathrm{O}-\mathrm{H}$ bending vibration from adsorbed water, and one band at $520 \mathrm{~cm}^{-1}$ assigned to $\mathrm{Mg}-\mathrm{O}$ vibration ${ }^{1,5}$. After acid activation, some changes in the FTIR spectra can be observed. In the high-energy range, the band

Table 1. EDS Semi-quantitative analyses for the clays samples.

\begin{tabular}{lccc}
\hline \multirow{2}{*}{ Samples } & \multicolumn{3}{c}{ Atomic \% ratio } \\
\cline { 2 - 4 } & $\mathrm{Si} / \mathrm{Mg}$ & $\mathrm{S} / \mathrm{Mg}$ & $\mathrm{Ag} / \mathrm{S}$ \\
\hline $\mathrm{LNa}$ & 1.9 & - & - \\
$\mathrm{LH}$ & 2.4 & - & - \\
$\mathrm{LHSH}+\mathrm{Ag}$ & 3.5 & 0.8 & 0.9 \\
\hline
\end{tabular}

$\mathrm{LHSH}+\mathrm{Ag}$ indicates the functionalized Laponite after silver adsorption. intensity at $3800-2600 \mathrm{~cm}^{-1}$ and at $1640 \mathrm{~cm}^{-1}$ increase, thus suggesting that the LH sample is more hydrophilic than the LNa. It is possible to observe a broadening of the band assigned to the $\mathrm{Si}-\mathrm{O}$ and $\mathrm{Si}-\mathrm{O}-$ Si stretching vibrations, an indication that acid activation may have promoted some minor structural modification. After functionalization, the LHSH sample shows the characteristic $\mathrm{SH}$ stretching vibration at $2562 \mathrm{~cm}^{-1}$ and $\mathrm{CH}$ stretching vibration at $2800-3000 \mathrm{~cm}^{-1}$, thus indicating that the organic molecules were effectively grafted to the surface silanol groups ${ }^{20}$. The relatively lower intensity of the band centered at $3450 \mathrm{~cm}^{-1}$ and the $\delta(\mathrm{O}-\mathrm{H})$ deformation band at $1640 \mathrm{~cm}^{-1}$ indicates a reduction of the adsorbed water content, with a consequent increase of the hydrophobicity of the LHSH sample.

Figure 3 presents the weight loss and the peak of the first derivative in order to illustrate the most significant events regarding weight loss events. In contrast to the original clay, which that does not show any important weight loss in the temperature range of $200{ }^{\circ} \mathrm{C}$ to $600{ }^{\circ} \mathrm{C}$, the functionalized sample exhibits a sharp DTG peak at 280-330 ${ }^{\circ} \mathrm{C}$. This feature was mainly ascribed to the loss of the mercaptopropyl group. A smaller and broader peak is also observed at temperatures of $700{ }^{\circ} \mathrm{C}$. This typical behavior of organoclays can be used as an indication of how much organic has been loaded onto the clay particles ${ }^{10}$. At higher temperature $\left(\sim 780{ }^{\circ} \mathrm{C}\right)$, the dehydroxylation of the clay sheets takes place. The increase of hydrophobicity following functionalization is indicated by the decrease of adsorbed water from 14.5 to $5.1 \%$ for the LH and LHSH samples, respectively, at $30-200{ }^{\circ} \mathrm{C}$. Taking into account the weight loss in the range 200 to $700{ }^{\circ} \mathrm{C}$, one may calculate $1.7 \mathrm{mmol}$ of mercaptopropyl groups per gram of grafted clay. Comparing this value to the binding capacity

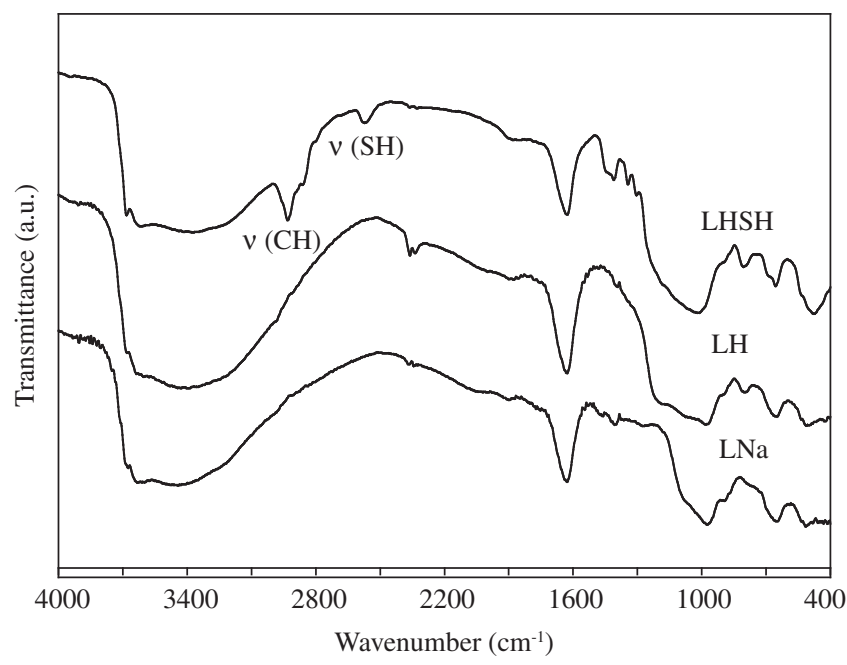

Figure 2. FTIR spectra of sodium (LNa), acid activated ( $\mathrm{LH}$ ) and functionalized (LHSH) laponite samples.

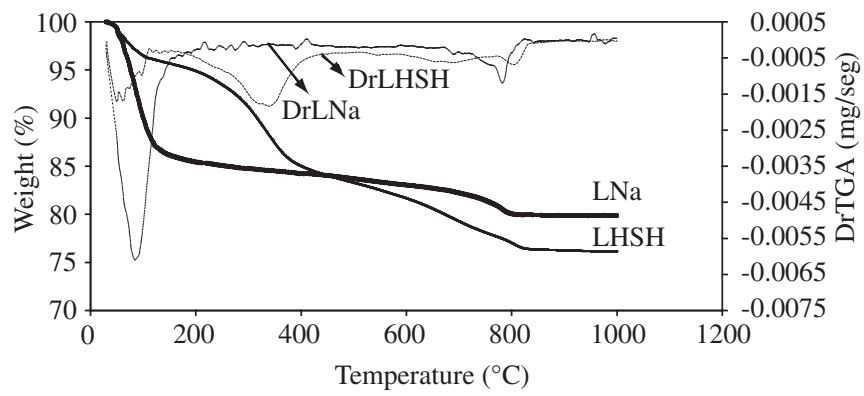

Figure 3. TG and DrTG curves of laponite samples. 
(1.4 meq/g) determined by the Volhard Method we assume that $82 \%$ of $\mathrm{SH}$ group are actually accessible to complexation of $\mathrm{Ag}^{+}$ions. This finding is in good agreement with accessibility of $90 \%$ inferred by the atomic $\mathrm{Ag} / \mathrm{S}$ ratio determined by EDS analysis (Table 1). For comparative purposes, a sample of laponite-Na was submitted to the same modification process but without acid activation. A value of $0.83 \mathrm{mmol}$ of mercaptopropyl groups per gram of grafted clay was determined by TG analysis, $104 \%$ less than the previous of $1.7 \mathrm{mmol} /$ g. Therefore, the acid pretreatment showed a significant influence on improving the grafting process without collapse of the structure. It is interesting to notice that the differences in the temperature of dehydroxylation (at $780{ }^{\circ} \mathrm{C}$ in LNa sample and at $808{ }^{\circ} \mathrm{C}$ in LHSH) suggests changes in the structure after the grafting process.

As illustrated in Figure 4, the XRD patterns for all the laponite samples are quite similar, with only the reflection at $2 \theta \sim 28^{\circ}$ showing some loss of definition. A comparison of the overall patterns indicates that the original structure was preserved after modification. The main d- spacing parameters of all samples are indicated. An approximate value of $1.25 \mathrm{~nm}$ was estimated for the interlayer distance in the $\mathrm{LNa}$ sample, despite the broadness of the $d_{001}$ peak. Other authors report similar findings, which were attributed to the very low dimensions and low crystallinity of the laponite crystals ${ }^{5,19}$. Acid activation led to an increase in the interlayer spacing ( 1.25 to $1.47 \mathrm{~nm})$, most likely due to water adsorption. The increased hydrophilic feature of the LH sample with respect to the starting laponite was previously indicated by the DRIFT spectra. No significant differences were observed in the basal spacing of the LH and LHSH samples (from 1.47 to $1.54 \mathrm{~nm}$ ). Normally, the intercalation of molecules in interlayer region of clay mineral cause significant changes in the interlayer distance ${ }^{19}$. In spite of this, it was observed by TG analysis an important decreasing in amount of adsorbed water. Usually the decrease of water content causes a significant decreasing in $\mathrm{d}_{001}$ spacing ${ }^{10}$. Taken into account that such reduction has not happened, our hypothesis is that there was replacement of some water molecule to organosilane in interlayer region of the clay. It indicates that silylation may take place at the surface of the particles and also within the interlayer galleries. Prado et al. and Park et al. report similar results ${ }^{17,19}$. It was possible to observe that the peak $\mathrm{d}_{001}$ becomes broader and less intense following

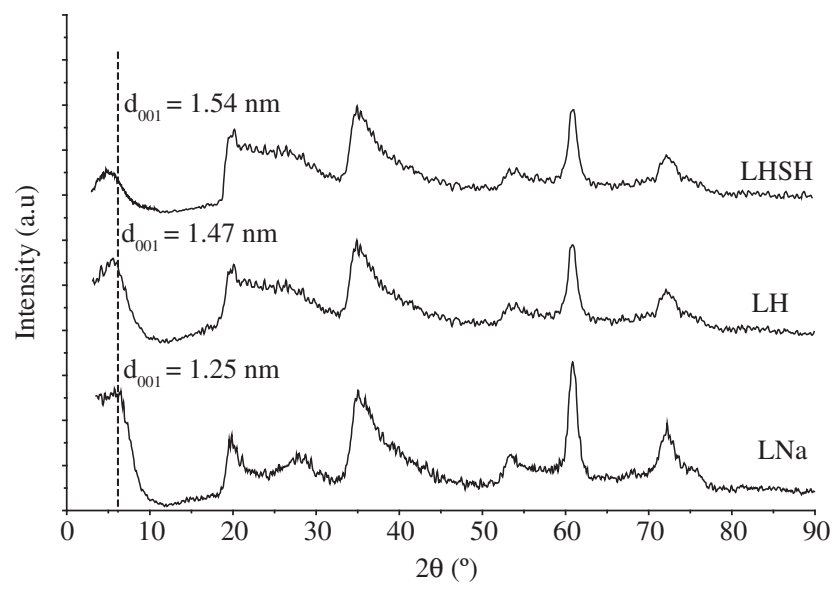

\begin{tabular}{|c|c|c|c|c|}
\hline Sample & & d-spacing/nm (Bragg a & angle/degree) & \\
\hline $\mathrm{LNa}$ & 1.25 (7.0); & $0.45(19.6) ; 0.32(28.1)$ & 0.25 & $0.15(60.8)$ \\
\hline LH & 1.47 (6.1); & 0.45 (19.6); broad & $0.26(34.1)$ & $0.15(60.8)$ \\
\hline LHSH & 1.54 (5.6); & 0.45 (19.6); broad & $0.26(34.1)$ & $0.15(60.8)$ \\
\hline
\end{tabular}

Figure 4. XRD patterns of sodium (LNa), acid activated ( $\mathrm{LH}$ ) and functionalized (LHSH) laponite. The inset shows the precise peak indexation. functionalization, thus indicating that this process may have caused some degree of disorder of the crystallites.

Figure 5a shows a SEM micrograph of the Na-laponite sample. One may observe particles formed by agglomerates of irregular

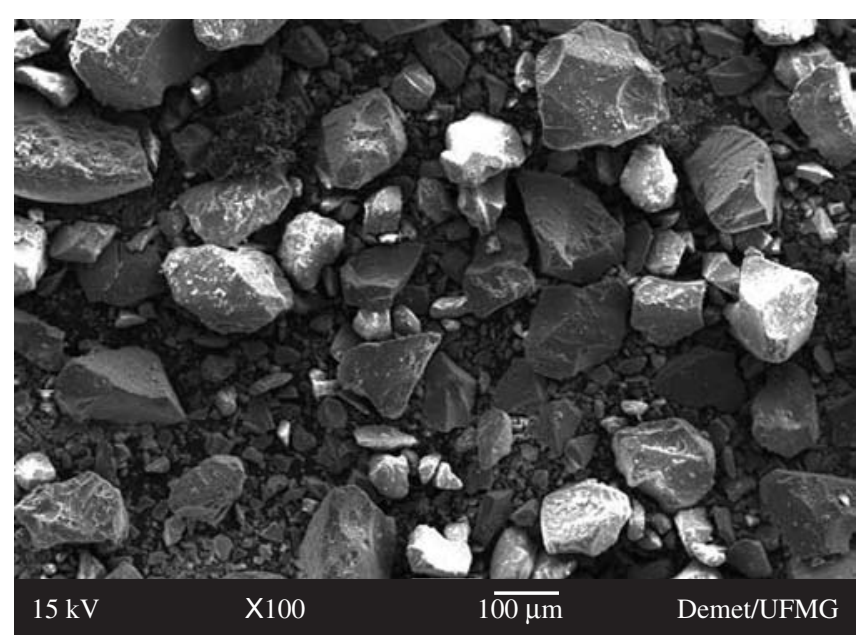

(a)

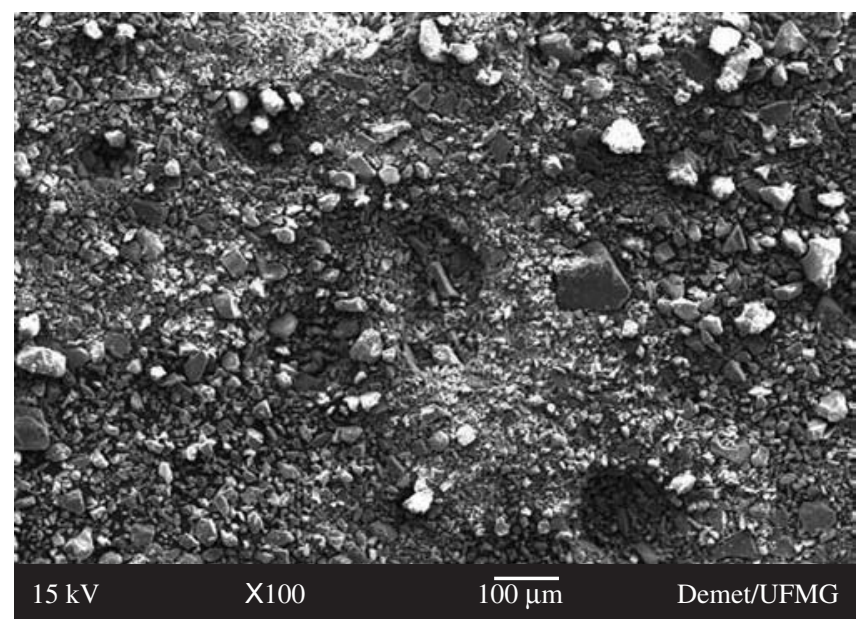

(b)

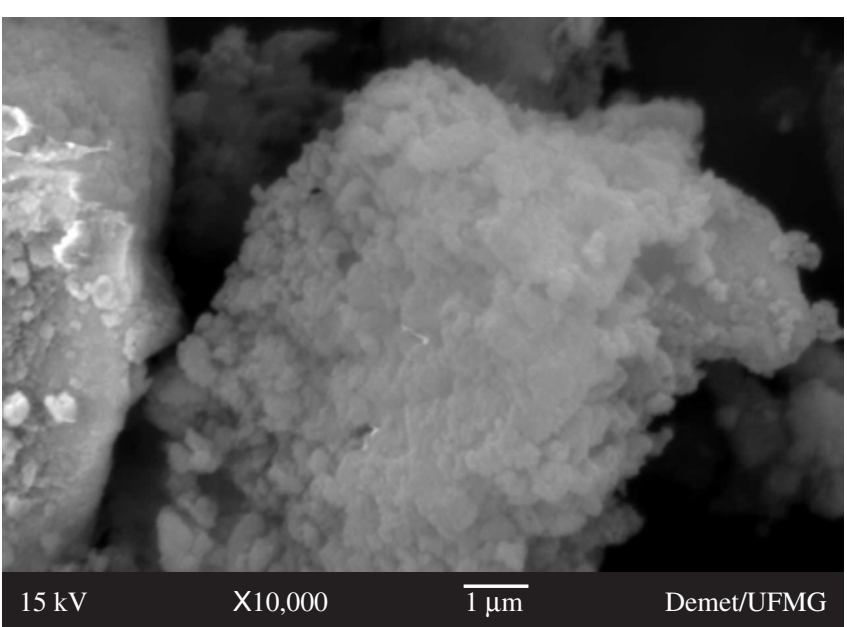

(c)

Figure 5. SEM micrographs of a) sodium laponite (LNa), b) and c) functionalyzed laponite (LHSH). 
shapes and flat surfaces. The strong tendency toward aggregation and the compact aspect of the material can be observed. The images $4 \mathrm{~b}$ and $4 c$ display the SEM micrographs of the functionalized clay. In this case, the particles are apparently smaller in size than the previous sample and are composed of disordered thin sheet particles aggregates (Figure 5c). One can conclude that functionalization promotes the formation of disordered and less cohesive aggregates, probably due to a reduction of the edge-to-edge and face-to face interactions. Unlike the hydrophilic laponite (LNa), which formed large size aggregates after drying, the LHSH sample was hardly dispersed in water (hydrophobic) and easily kept as a loose powder after drying. This change constitutes an important advantage considering the product application in commercial units.

\section{Conclusion}

Laponite, a synthetic silicate, was functionalized through a straightforward reflux with organosilanes, in a route that seems attractive for the preparation of a selective sorbent for biomolecules. Analyses by XRD showed that the silylation process did not significantly affect the crystallographic structure of the clay as no important changes were observed in the basal spacing after functionalization. Analyses by XRD and TGA analysis showed that the silylation drastically reduced adsorbed water without causing basal spacing contraction, suggesting that intercalation may have occurred also in the interlayer region. The DRIFT results confirmed the presence of thiol groups and organic compounds on the modified clay. The Volhard method indicated a binding capacity of $1.4 \mathrm{meq} / \mathrm{g}$ of clay and this method showed to be a fast and efficient methodology for binding capacity determination to be applied to thiol functionalized substrates.

\section{Acknowledgments}

The authors thank CNPq and FAPEMIG for the financial support.

\section{References}

1. Celis R, Hermosín MC, Cornejo J. Heavy metal adsorption by functionalized clays. Environmental Science and Technology. 2000; 34(21):4593-4599.

2. Coche-Guérente L, Desprez V, Labbe P. Characterization of organosilasesquioxane-intercalated-laponite-clay modified electrodes and (bio)electrochemical applications. Journal of Electroanalytical Chemistry. 1998; 458(1):73-86.

3. He H, Duch et J, Galy J, Gerard JF. Grafting of swelling clay materials with 3-aminopropyltriethoxysilane. Journal of Colloid and Interface Science. 2005; 288(1):171-176.

4. Patil AJ, Muthusamy E, Mann S. Fabrication of functional protein-organoclay lamellar nanocomposites by biomolecule-induced assembly of exfoliated aminopropyl-functionalized magnesium phyllosilicates. Journal of Materials Chemistry. 2005; 15(35):3838-3843.

5. Kuz'niarska-Biernacka I, Silva AR, Carvalho AP, Pires J, Freire C. Organo-Laponites as Novel Mesoporous Supports for Manganese(III) salen Catalysts. Langmuir. 2005; 21(23):10825-10834.

6. Walcarius A, Etienne M, Delacote C. Uptake of inorganic $\mathrm{Hg}$ (II) by organically modified silicates: influence of $\mathrm{pH}$ and choride concentration on the binding pathways and electrochemical monitoring of the processes. Analytica Chimica Acta. 2004; 508(1):87-98.

7. Bois L, Bonhommé A, Ribes A, Pais B, Raffin G, Tessier F. Functionalized silica for heavy metal ions adsorption. Colloids and Surfaces A: Physicochem. Eng. Aspects. 2003; 221(1):221-230.

8. Mansur HS, Vasconcelos WL, Lenza RFS, Oréfice RL, Reis EF, Lobato ZP. Sol-Gel silica based networks with controlled chemical properties. Journal of Non - Crystalline Solids. 2000; 273(1):109-115.

9. Mercier L, Pinnavaia T J. A functionalized porous clay heterostructure for heavy metal ion $\left(\mathrm{Hg}^{2+}\right)$ trapping. Microporous and mesoporous materials. 1998; 20(1):101-106.

10. Mercier L, Detellier C. Preparation, Characterization and Applications as Heavy metals sorbents of covalently grafted thiol functionalities on the interlamelar surface of montmorillonite. Environmental Science and Technology. 1995; 29(5):1318-1323.

11. Sayilkan H, Erdemoglu S, Sener S, Sayilkan F, Akarsu M and Erdemoglu M. Surface modification of pyrophyllite with amino silane coupling agent for the removal of 4-nitrophenol from aqueous solutions. Journal of Colloid and Interface Science. 2004; 275(2):530-538.

12. Park KW, Kwon OY. Interlamellar silylation of montmorillonite with 3-aminopropyl-triethoxysilane. Bull. Korean Chemistry Society. 2004; 25(7):965-968

13. Mousty C. Sensor and biosensor based on clay-modified electrodes-new trends. Applied Clay Science. 2004; 27(3):159-177.

14. Tonle AK, Ngameni E, Walcarius A. From clay-to organoclay-film modified electrodes:tunning charge selectivity in ion exchange voltammetry. Electrochimica Acta. 2004; 49(20):3435-3443.

15. Tietjen T, Wetzel RG. Extracellular enzyme-clay mineral complexes: Enzyme adsorption, alteration of enzyme activity and protection from photodegradation. Aquatic Ecology. 2003; 34(4):331-339.

16. Bruce T, inventor. Process to remove protein and other biomolecule from tobacco extract or slurry. US patent 20060037620. 2006 Feb 23.

17. Prado LAS, Karthikeyan ACS, Schulte K, Nunes SP, Torriani IL. Organic modification of layered silicates: structural and thermal characterizations. Journal of Non-Crystalline Solids. 2005; 351(12):970-975.

18. Dominguez L, Yue Z, Economy J, Mangun CL. Design of polyvinyl alcohol mercaptyl fibers for arsenite chelation. Reactive \& Functional Polymers. 2002; 53(2):205-215.

19. Park M, Shim IK, Jung EY, Choy JH. Modification of external surface of laponite by silane grafting. Journal of Physics and Chemistry of Solids. 2004; 6(2):499-501.

20. Coates J. Interpretation of infrared spectra, a practical approach. In: Meyers A. editor. Encyclopedia of Analytical Chemistry. Chichester: John Wiley \& Sons Ltd; 2000. p. 10815-10837. 
